\title{
IMPACTOS DO TRABALHO NA FORMAÇÃO DO ACADÊMICO EM PSICOLOGIA: RELAÇÕES OBRIGATÓRIAS NO TEMPO DA UNIVERSIDADE
}

\section{ARTIGO DE REVISÃO}

RAMOS, Marcos de Melo ${ }^{1}$

PURIFICAÇÃO, Marcelo Máximo ${ }^{2}$

RAMOS, Marcos de Melo. PURIFICAÇÃO, Marcelo Máximo. Impactos do trabalho na formação do acadêmico em Psicologia: relações obrigatórias no tempo da universidade. Revista Científica Multidisciplinar Núcleo do Conhecimento. Ano 04, Ed. 10, Vol. 06, pp. 18-32. Outubro de 2019. ISSN: 2448-0959, Link de acesso: https://www. nucleodoconhecimento.com.br/psicologia/formacao-doacademico

\section{RESUMO}

O presente texto é fruto de um trabalho de conclusão de curso desenvolvido no âmbito da licenciatura em psicologia no Centro Universitário de Mineiros - UNIFIMES - Goiás. Teve como objetivo, compreender a relação entre formação inicial do psicólogo em concomitância com o trabalho. Para atender ao objetivo proposto, foram utilizadas a pesquisa qualitativa, quantitativa e de opinião sobre as questões propostas. Constatase que um número significativo de estudantes, conciliam as práticas de estudo e trabalho e, em alguns casos, os alunos que trabalham apresentam rendimentos melhores.

Palavras-chave: Formação, trabalho, divergências, psicologia.

\footnotetext{
${ }^{1}$ Acadêmico de Psicologia.

2 Pós-Doutor em Educação pela Universidade de Coimbra. Doutor em Ciências da Religião pela PUC-Goiás.
} 


\section{INTRODUÇÃO}

Conciliar o trabalho com a vida acadêmica é um grande desafio para o processo de ensino e aprendizagem. Muitos acadêmicos trabalham em funções contrárias à sua formação. Com isso pode-se pensar que as funções não estão sendo qualificadas pelo conhecimento e consequentemente afetará a demanda do mercado de trabalho e excluirá as possibilidades de o trabalhador construir uma carreira. Diante do exposto faz-se necessário estudos que possam colaborar para a quebra deste paradigma construído entre educação, economia e sociedade. Isto dito, indaga-se: Os acadêmicos na vida ativa universitária conciliam o trabalho externo com os seus estudos de forma a agregar valor entre conhecimento e trabalho? Esta pesquisa, cujo objetivo é a relação entre a formação do psicólogo e o trabalho, torna-se relevante por ser uma forma de identificar e dialogar sobre a temática. Tais fatos relacionam com a minha vivência que experiencia a realidade de trabalhar e estudar, o que possibilita um olhar mais crítico e analítico acerca do tema.

Vale apontar a importância de compreender como se desenvolve a junção formação acadêmica/trabalho e como se apresenta ambivalência de ambos em suas principais colocações, tomada de tempo, e os conflitos (internos e externos) apresentados perante tal realidade. A priori este trabalho contribuirá para a reflexão e compreensão da realidade de muito dos acadêmicos que possui em si a obrigatoriedade do trabalhar para que possa manter a vida acadêmica.

\section{O INGRESSO À FORMAÇÃO ACADÊMICA}

Para o acadêmico inicialmente a faculdade está para ele como um ambiente novo, este que o leva a construir sonhos e expectativas acerca da experiencia que irá vivenciar durante este período. Porém, no que tange tais experiencias, em muito dos casos, são frustradas pois serão atravessados pela realidade ainda inexplorada por estes calouros.No Brasil quando se trata da temática formação superior e profissional, conforme Rodrigues, Machado e Araújo (2012) é visível a entrada da população com menor renda nas universidades, deixando parcialmente de ser elitizado, como se desenvolvia na década 70 , pois apenas quem possuía um diploma de graduação eram 
indivíduos que tinham uma quantidade de bens considerável para a época, financeiramente, a possibilidade de obter um curso superior.

Durante muitos anos o acesso ao Ensino Superior era um privilégio das elites sociais. A escassa oferta de vagas e de cursos superiores associados à concentração das IES nas grandes cidades e os custos com a frequência deste nível de ensino dificultavam o acesso de parte da população. A partir da década de 70 do século $X X$, assiste-se a um processo de expansão do Ensino Superior em resultado da necessidade de democratizar o acesso a este nível de ensino a toda a população, com base em estudos realizados por organizações internacionais, como a UNESCO, a OCDE e o Banco Mundial, que mostravam uma relação direta entre o nível de desenvolvimento do país e o nível de escolaridade da população. (RODRIGUES; MACHADO; ARAUJO, 2011, p. 2).

Tal fala demonstra diversas mudanças ocorridas a partir dos acontecimentos históricos que marcaram a historicidade do Brasil, na iniciativa de mudança que vemos a entrada na vida acadêmica por parte de toda a população, movimento em favor da democratização estudantil e igualdade dos direitos. Mesquita (2010) menciona que, diferente de muitos que já estavam na função de acadêmico mantidos financeiramente pelos pais, a população menos favorecida tem a necessidade de cumprir dois papeis que se destoa um do outro estudar e trabalhar. Nota-se diferenças de atuações estudantis por conta da situação econômica de cada estudante, por isso acarreta necessidade do trabalho em meio acadêmico. Sobre isso Mesquita (2010) reafirma que:

Na formação dos estudantes trabalhadores e a escassez de renda que traz como consequência a falta de tempo para dedicação aos estudos. Tempo necessário e adequado para que este sujeito possa estudar e se profissionalizar em um curso com qualidade, quebrando definitivamente o ciclo de despreparo constatado pelos resultados pífios da educação no Brasil em relação aos países em desenvolvimento e desenvolvidos. (MESQUITA 2010, p. 168)

Neste sentido compreende-se que há possibilidade de identificar ambivalências constituídas pelos meios já existentes entre a relação educação (formação da pessoa) e o trabalho (mão de obra) que preexistem na vida do homem. O que vem ser confirmado por Colombo e Ballão (2014), onde a legislação brasileira entrou em discussão sobre o estágio remunerado, o qual apresentara uma ambivalência de 
demanda, porque visava por um lado, atender o interesse educacional e por outro deveria atender o mercado financeiro empresarial.

No que se refere ao estágio remunerado, conforme Brasil (s/d), a Lei 11.788/2008 traz toda compreensão sobre a relação do mercado de trabalho com o estudante em fase de estágio, a qual através dos arts.12, 13 e 14 estabelece o tempo de vínculo com a empresa e a garantia do estudante para esse fim laboral por meio do conceito 'bolsa'. E o que nos remete refletir sobre a ambivalência mencionada por Colombo e Ballão (2014) são alguns fatores como o tempo de serviço por dois anos, mas não dá os direitos que um trabalhador tem garantido pela Constituição Brasileira (1988/2012), Capítulo II dos Direitos Sociais, disposto no art. $7^{\circ}$. Fato esse coloca o estagiário a se sentir inseguro, o qual vive as tensões de qualquer momento poderá ser desvinculado sem garantias, e a ameaça eminente se estende para a possibilidade de não poder estudar. Ao senso comum pode-se ouvir muitos estudantes afirmar não sair do trabalho de carteira assinada para o estágio remunerado pelo fato da insegurança. $O$ que se estende para submissão de funções nada a ver com sua formação.

O que não se pode negar são as possibilidades de estágio remunerado pelo fato de as questões econômicas de muitos estudantes serem baixa. Por isso o estudante se submete ao labor e estudo ao mesmo tempo. Desse modo, conforme Borges e Yamamoto (2004) pode-se entender que o trabalho é um fator que leva o indivíduo a submeter-se para se sustentar, em sincronia a isso tem a necessidade de formação para ampliar conhecimento e consequentemente evoluir nas conquistas de funções. Porque, a produção da força de trabalho depende do desenvolvimento da ciência e de sua aplicação tecnológica, e o mundo de produção, extensão e eficácia são condições para o trabalhador. Isso justifica as atuações de indivíduos que estudam e trabalham, ou seja, há uma (co) dependência entre o trabalho e o conhecimento.

Os estudantes do Ensino Superior do período noturno necessitam trabalhar para se manterem em seus cursos, mas senti a necessidade de prosseguir na discussão destas condições de acesso e permanência neste nível de ensino com o intuito de desvelar as intenções contidas nos discursos políticos que defendem o acesso do Ensino Superior noturno como uma oportunidade de formação sem a preocupação com a qualidade desta formação. Quando falo em permanência no Ensino 
Superior refiro-me a uma permanência com qualidade, ou seja, com sucesso, que pode verdadeiramente contribuir na formação destes profissionais de sorte que possam, a partir da conclusão de seu curso, enfrentar os desafios do mercado de trabalho. Mesquita (2010, p. 28)

Zanelli (2002) vem reforçar as ideias de Borges e Yamamoto (2004) e de Mesquita (2010) sobre a correlação entre conhecimento e trabalho, dentro da perspectiva educacional se adota a ideia de desenvolvimento das potencialidades da pessoa, as quais torna-se competente na resolução de problemas e capacidade de ajustar-se a novas situações de forma autônoma e criativa. Neste sentido nos deparamos com realidades que se associam de forma dependente, como já afirmado, e ainda convém apontar que Zanelli (2002) argumenta que, em uma sociedade, a relação acontece entre um sistema educacional pensado na habilitação de pessoas para o mercado de trabalho através da educação, um sistema capitalista pautado na lucratividade e mão de obra, e por fim o sistema pessoal de cada indivíduo.

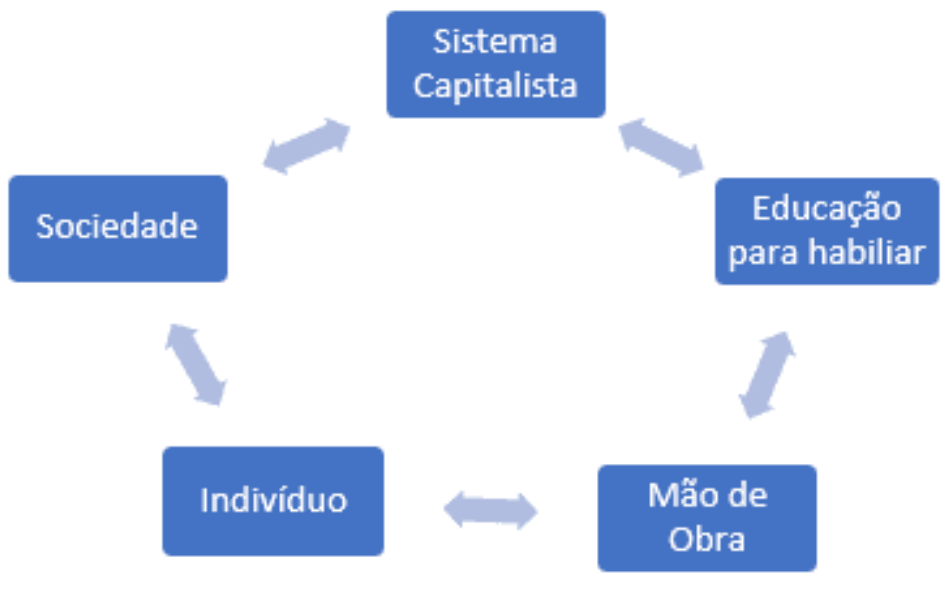

Fonte: o próprio autor

A partir da analogia é disponibilizado pensamentos que se voltem para a formação de pessoas para o "mundo", suas necessidades e exigências quando nos referimos a este individuo inserido no mundo do trabalho que detém em si o labor de cada atividade exercida, que está ligado também ao ensino superior mais específico a formação do psicólogo, e a relação estabelecida com o mundo do trabalho durante o 
período acadêmico, que irá se estabelecer seja de forma dialógica ou até mesmo de forma oposta. E para isso inicialmente se faz necessário entender o processo de formação do psicólogo como ponto de partida para análise que será acometida posteriormente.

Verificando a fala de Duran (1983, p. 13), onde afirma que "(...) temos de nos voltar para nossos cursos, analisar cuidadosamente as variáveis envolvidas e experimentar". Podemos visualizar um olhar voltado a uma formação que se desenvolve a partir de uma análise situacional, bem como as demandas levantadas na formação do profissional, que necessita da averiguação mais específica, e o trabalho durante a formação.

\section{A FORMAÇÃO DO PSICÓLOGO NA PERSPECTIVA DA PSICOLOGIA ORGANIZACIONAL}

Segundo Zanelli (2002) a formação do psicólogo se modificou de forma considerável, porém tais mudanças se deram em modelos restritos a modificações apenas em nomes e disciplinas das ementas que constituem cada curso. Em tudo, para que possa ser ajustado todas as (pré) determinações para os procedimentos executores, para a formação desse acadêmico. Se faz necessário uma análise aprofundada acerca das necessidades apresentadas em relação com o exercício da profissão e todas exigências da formação, e do mercado de trabalho que é estabelecido por Zanelli em três pilares: capacidade, limitações e necessidades dos alunos.

A formação do psicólogo vivencia momentos em que o ensino não se encontra voltado ao educando e sim para uma profissionalização que abrange para um sistema que se diz formador, mostrando para a população uma realidade que se baseia em uma realidade visual mostrando apenas o quantitativo de acadêmicos que estão se formando, afirmado por Zanelli (2002, p. 12). Dentro de limites relativos, encontramse estereótipos e dificuldades ligados ao exercício profissional em qualquer campo de atuação. Demonstrando um despreparo profissional no que tange a formação profissional do indivíduo aliado ao mundo de trabalho, exigindo assim funções que demandam tempo e dedicação bem como exigida pelas escolas de ensino superior 
durante a formação. Sendo a pessoa um estudante trabalhador, como relacionar a formação profissional e o mercado de trabalho? O que tomar como prioridade, se o indivíduo necessita do emprego para manter a vida acadêmica?

A partir de tais questionamentos se faz necessário pensar nesta relação como algo relevante, levando em consideração o pensamento deste estudante, e como ele tem visto a própria formação. Uma pesquisa feita por Borges-Andrade e colaboradores (1983) afirma que $32,4 \%$ dos psicólogos que atuam no distrito federal dizem que seus cursos são bastante ou totalmente insuficiente, comprometendo a profissão como um todo.

\section{METODOLOGIA}

Para classificar o tipo de pesquisa, segundo Vergara (2004), torna-se como referência como o critério de classificação quanto à sua natureza, quanto aos fins e quanto aos meios. Quanto à natureza, classifica-se à presente pesquisa como quantitativa para empregar dados estatísticos para um processo de análise do problema exposto no mesmo. Quanto aos fins, classifica-se como uma pesquisa descritiva dos dados, haja vista que se busca descrever a relação da formação do psicólogo e o trabalho.

Rampazzo (2005) afirma que, a metodologia nos ensina o caminho a percorrer de um estudo científico através de normas e técnicas. Para isso o homem precisa adentrar nas diversas áreas da realidade para conhecê-la em sua própria verdade e/ou transformá-la satisfazendo suas necessidades. Fato este, conveniente ao presente estudo, porque alguns recortes de uma ciência e outra, como a Psicologia Organizacional, Educação e Sociologia, permitindo a execução dessa pesquisa de campo.

Então, busca-se conduzir o caminho científico através de estudos teóricos e levantamento de dados estatísticos para obter informações que possam atender os objetivos elaborados para o mesmo. Foi utilizado um conjunto regras para estruturação da investigação desse estudo. Como levantamento bibliográfico referente ao tema; elaboração um questionário quantitativo que permite levantar os 
dados estatísticos sobre o estudo acadêmico e trabalho. Vale ressaltar que para a afirmação da teoria apresentada foi feito uma pesquisa para levantamento estatístico, utilizando exatamente 72 acadêmicos selecionados aleatoriamente, estudantes do Centro Universitário de Mineiros- UNIFIMES, que cursam psicologia. Utilizamos então um questionário cujo procedimento aplicado para a entrevista foi um questionamento de abordagem direta e objetiva, que tem como objetivo resumir em dados estatísticos a relação da formação e o trabalho.

\section{RESULTADOS E DISCUSSÕES}

Após a leitura e diálogo com os teóricos foi possível constatar a importância da formação do psicólogo e suas implicações com o trabalho. Foi possível ainda compreender que o mundo do trabalho contemporâneo requer competências e habilidades funcionais que não podem ser constituídas de forma desassociada com a formação acadêmica, isto dito percebe-se uma relação de suma importância entre a formação do psicólogo e o trabalho.

Com o objetivo de entender a relação existencial dos alunos do curso de psicologia do Centro Universitário de Mineiros-UNIFIMES com o mundo do trabalho, buscamos então através de uma entrevista fechada e objetiva respostas que se relacionam, e ainda responda como acontece tal relação entre a formação e o mundo do trabalho. A entrevista esteve pautada em um número exato de questões, quatro no total, porém a partir das repostas identificas pudemos desenvolver uma quinta questão está que se vincula ao trabalho e a formação acadêmica. Para que inicialmente possamos identificar tal relação questionamos se o indivíduo possuía ou não vínculo empregatício, que segundo o gráfico a seguir, apresenta uma porcentagem mínima de diferença entre pessoas que trabalham quanto as que não trabalham. 
Gráfico 1: Questão 1. Você possui algum vínculo empregatício?

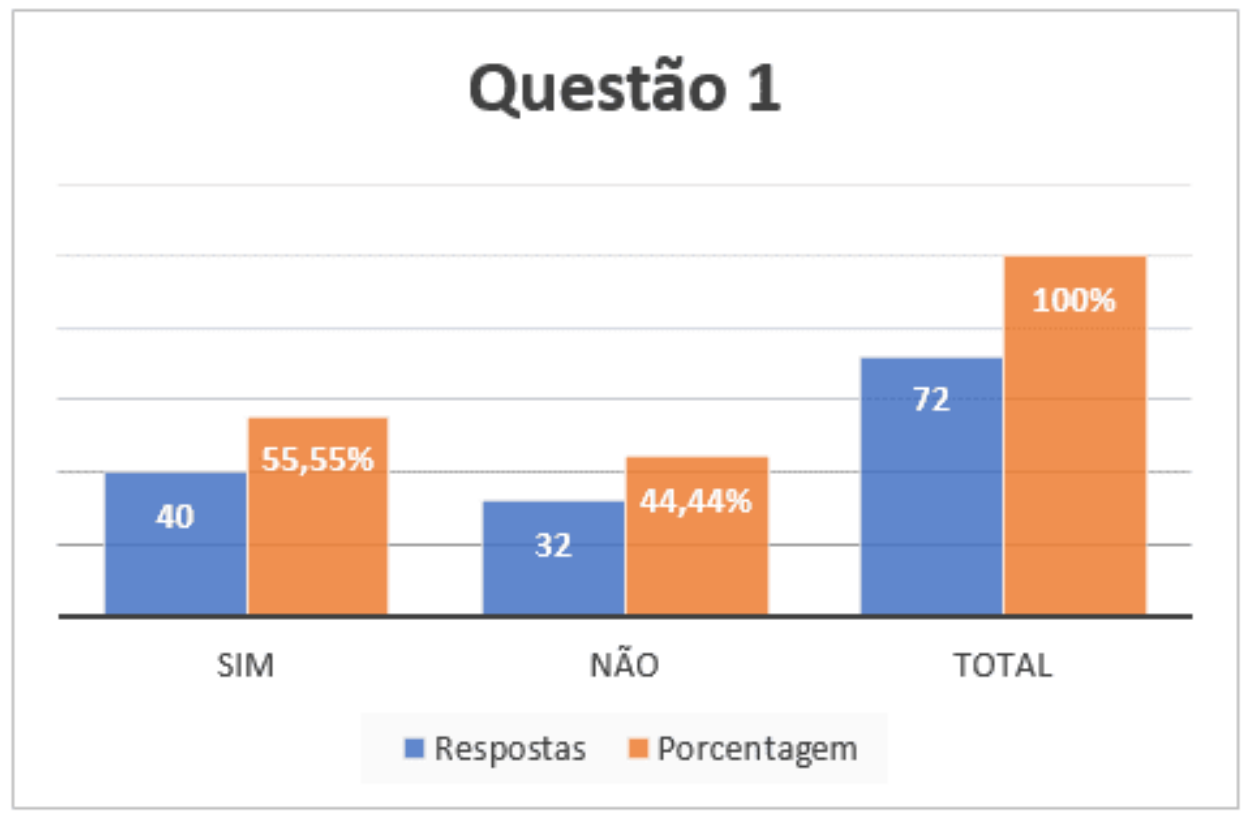

Fonte: Autor.

Tal gráfico explicita a ideia de que existem grupos que vivenciam o período universitário de forma diferente, e que segundo Romanelli (1995) apresenta as seguintes categorias: "estudante em tempo integral": este que não possui alguma atividade remunerada sendo então mantido financeiramente pelo responsável; "estudante-trabalhador": possui em grande maioria muitas das vezes há predominância de vínculo empregatício, porém segundo o autor esta categoria é pouca envolvida com o seu emprego, devido seu planejamento esteja voltado a sua qualificação no curso superior; "trabalhador-estudante" (1995, p. 453): dentro desta categoria o estudante mantem vínculo empregatício e ainda necessidade deste emprego para continuar no ensino superior, pois não são sustentados pelos pais, uma vez que o mesmo ainda contribui com parte do orçamento familiar. Para o autor esta classe toma a decisão de estudar de forma pessoal baseando-se em seus próprios valores constituídos durante a vida ou até mesmo por interesse na melhoria financeira e profissional.

Para entender, ainda de forma geral, se existe uma articulação do trabalho e formação do acadêmico, se este estudante tem a possibilidade de obter vínculos que estejam 
voltados a bolsas empregatícias, estas que possibilitam experienciar com mais complexidade o ramo de sua formação e dentro desta linha obtivemos um mínimo de respostas positivas, como apresentada no gráfico 2 da segunda questão.

Gráfico 2: Questão 2. Seu trabalho tem vínculo bolsista?

\section{Questão 2}

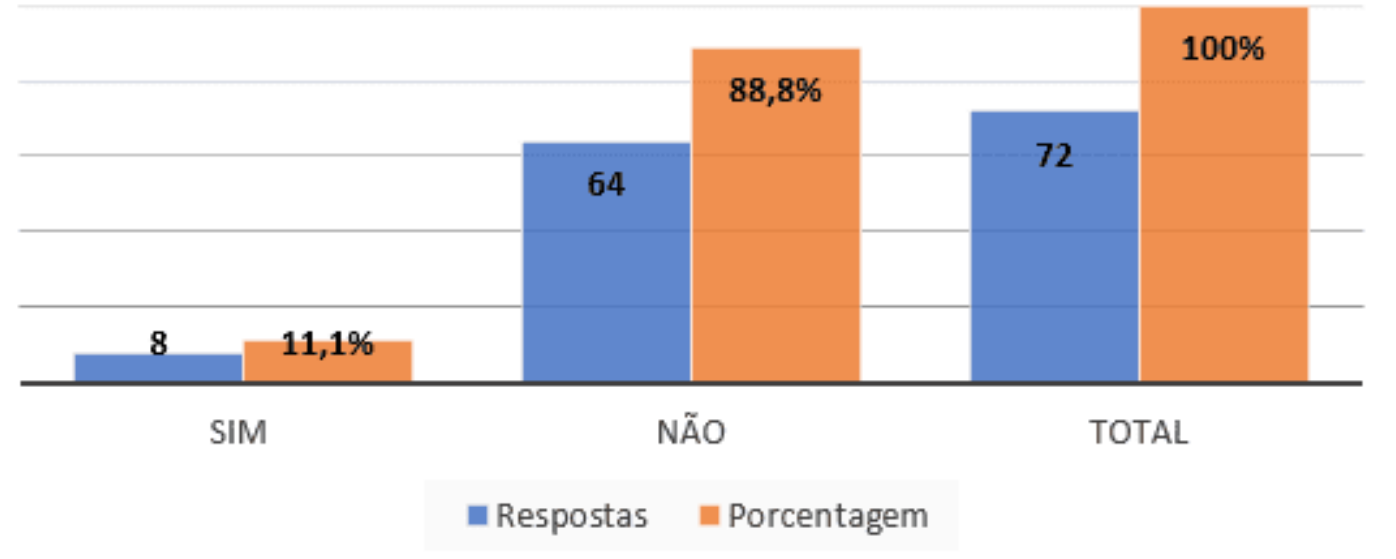

Fonte: Autor.

Dentro deste viés percebemos que o mundo do trabalho hoje pouco experienciado pelos universitários dentro de suas áreas de formação, não apresenta a necessidade/ interesse de possibilitar aos estudantes a um vínculo empregatício onde eles possam se ver dentro do mercado de trabalho anteriormente a sua formação. O que nos leva a pensar novamente na constituição que se refere ao estágio remunerado, lei esta que através dos art. 12, 13 e 14 firma que a empresa pode prestar ao estudante esta possibilidade, porem utilizam do termo bolsa para que não haja necessidade de ser criado vínculo empregatício o que deixa o indivíduo que recebe deste serviço em posição de fragilidade frente a direitos do trabalhador. Com isto buscamos identificar através da $3^{\circ}$ questão se algum dos entrevistados que trabalhavam, seja eles com vínculos empregatícios ou não, conseguiam encontrar em suas atividades laborais do 
dia a dia em funções que se relacionavam com a sua formação, apresentado no gráfico a seguir:

Gráfico 3: Questão 3. Seu trabalho tem relação com a sua formação?

\section{Questão 3}

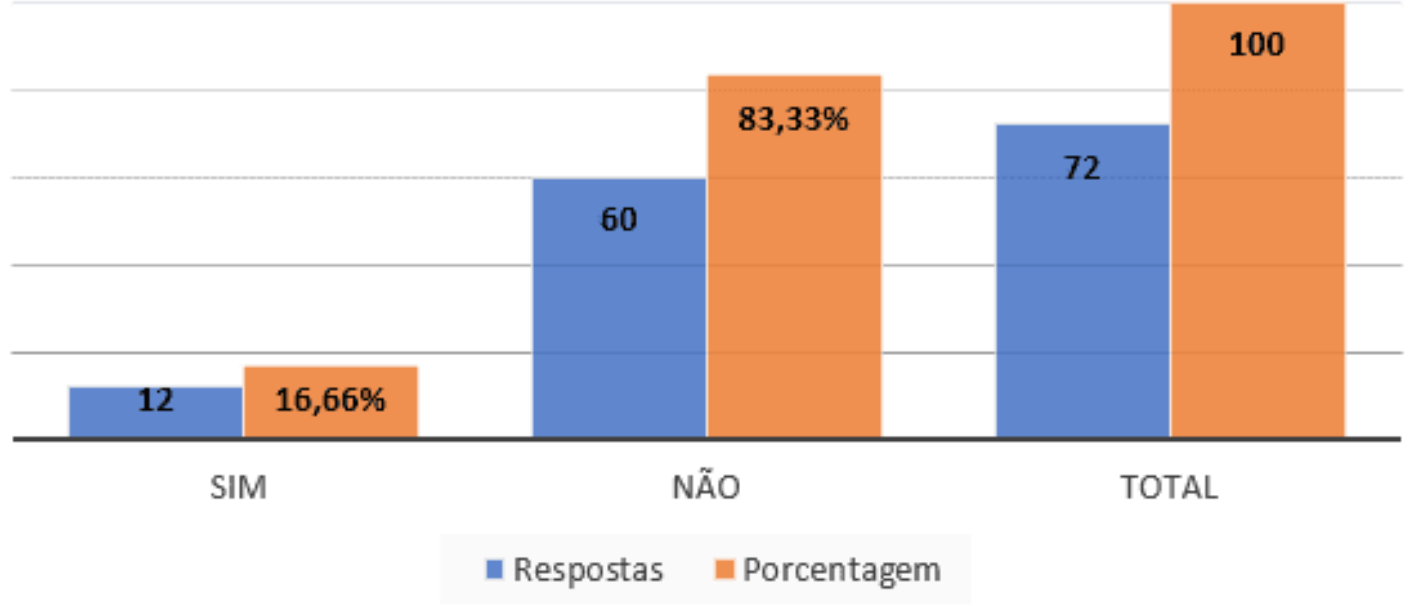

Fonte: Autor.

A partir das respostas do gráfico anterior, percebemos que a porcentagem de acadêmicos do curso de psicologia do Centro Universitário de Mineiros que possuem trabalho e que dentro de seu trabalho as funções se vinculam com a sua formação está em menos de $20 \%$, mais exatamente em $16,66 \%$ dos alunos entrevistados (72 alunos entrevistados). Fato este que mostra como é experienciado a realidade dos indivíduos. Vemos na questão 4 gráfico 4 o resultado onde mostra se este trabalha afeta o estudo. 
Gráfico 4: Questão 4. Seu trabalho afeta o seu estudo?

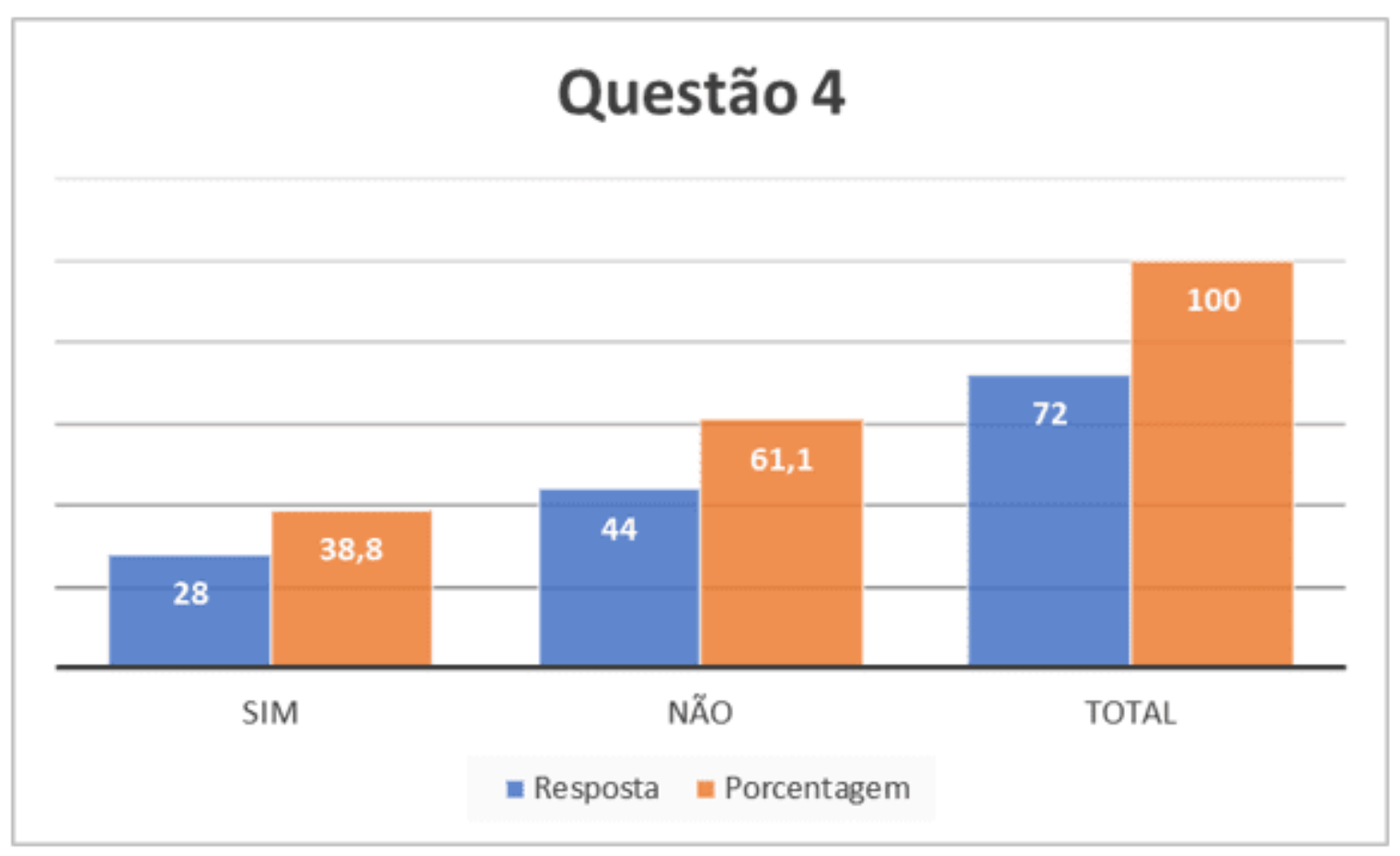

Fonte: Autor.

No que tange tais resultados, é valido ressaltar que a porcentagem que se remeta a questão engloba todos os indivíduos, estes que em grande parte não possuem vínculos empregatícios. Destacado pelo gráfico 1 onde 32 (44,44\%) dos 72 indivíduos entrevistados não possuem algum trabalho. Por isso acredita-se que a validade deste gráfico 4 é questionável, pois seria pouco provável que algum indivíduo que não possui vínculo empregatício afirmar que o mesmo afeta os seus estudos. Como consequência a questão 5 é formulada através dos dados já obtidos. Gráfico este que se pauta em mostrar apenas o quantitativo dos indivíduos que trabalham, quais foram as respostas deles quando nos remetemos novamente a questão 4, para assim sabermos ao certo se este que estuda sente ou não afetado pelo estudo de forma geral. 
Gráfico 5: Respostas tabuladas de pessoas que trabalham.

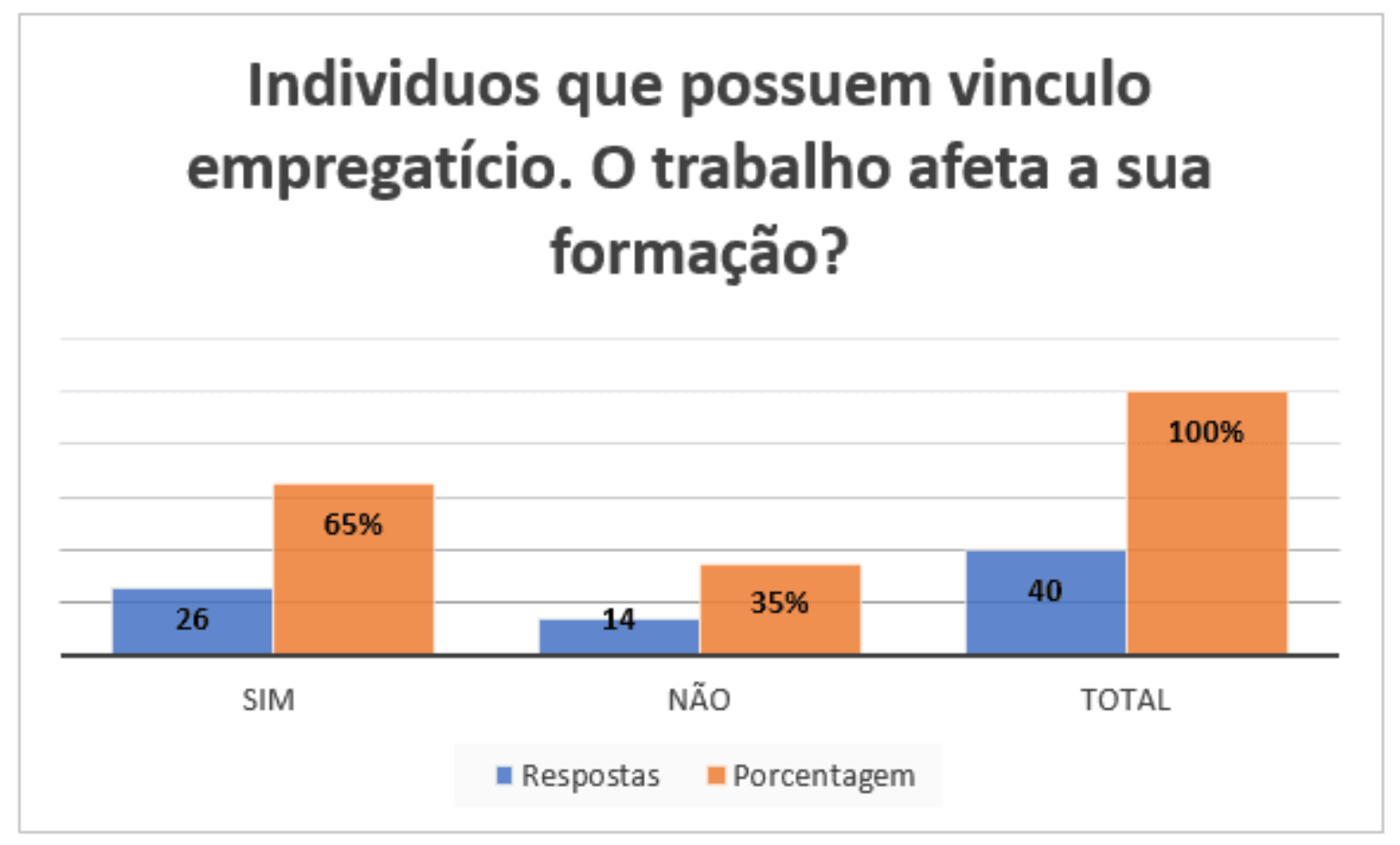

Fonte: Autor.

É visível diante do gráfico anterior a realidade expressa em números. Estudantes/trabalhadores sente-se em grande maioria (65\% dos 40 alunos que trabalham) afetados pela realidade que os mesmos estão atravessados diariamente devido a sua própria escolha. Uma vez que esta realidade possui uma interdependência para tais indivíduos. VARGAS; PAULA (2013) afirma que "Por vezes, o trabalho dificulta a escolarização, por vezes, a ausência de trabalho impede a escolarização" (p. 465), retratando mais uma vez que esta realidade, onde estes acadêmicos em especifico vivenciam esta pautado por questões que estão para além do ritmo de trabalha e estudar, abrange também a área financeira, estes acadêmicos dependem do trabalho para manter os custos provenientes das exigências da faculdade.

Frente a isso percebe-se que "o fator socioeconômico é o que determina mais fortemente o desempenho escolar dos estudantes" (BRASIL.INEP, 1999, p. 23) devido as exigências funcionais exigidas por ambas áreas -universidade e trabalho. Em 
oposição a ideia do aluno/trabalhador temos o aluno que não possui a necessidade de trabalhar este que em sua grande maioria tem a disposição de um tempo maior para o estudo integral, bem como afirma Vargas e De Paula:

Em direção diametralmente oposta, o aluno "não trabalhador" configura o "estudante em tempo integral", por oposição ao status de "trabalhadorestudante" ou de "estudante-trabalhador", sugerindo uma ótima disponibilidade de tempo para a realização de estudos. Liberado da obrigação de se sustentar, o estudante em tempo integral não só pode optar por carreiras que demandam investimento de tempo integral quanto poderá, no momento oportuno, trilhar o ritual do estágio que antecede a boa colocação profissional. (VARGAS; DE PAULA. 2012. p. 467).

A partir das afirmativas e dos dados qualitativos, a partir da pesquisa no Centro Universitário de Mineiros- UNIFIMES, teorizados anteriormente se faz necessário pontuar que a classe menos favorecida (trabalhador/estudante), segundo as políticas públicas de ensino são indivíduos que tem total acesso as instituições tanto públicas quanto privadas. Porém quando nos referimos as universidades privadas, estas políticas se resguardam a partir das bolsas de estudos disponibilizados pelo governo. Dando enfoque nestas bolsas disponibilizadas podemos olhar para o FIES- Fundo de Financiamento ao Estudante do Ensino Superior, como um dos principais mecanismos utilizados pelos indivíduos que se encontram impossibilitado de pagar o valor completo da mensalidade cobrada pela faculdade que ele egressa.

Mas como validar uma bolsa que na articulação para conseguir "se exige fiador com renda equivalente à, pelo menos, duas vezes o valor da mensalidade e se a renda familiar do candidato for inferior a $60 \%$ do valor da mensalidade, exige-se um segundo fiador nas mesmas condições do primeiro" (GISI, 2004, p. 2). Que política pública de ensino seria esta, que afirma ser para a classe baixa, se ela exige dos mesmos um fiador que disponibilize de uma condição financeira elevada, esta que pouco provável vem ser vivenciada por esta população de baixa renda. Ristoff e Pacheco (2004 p. 07) explana acerca das políticas públicas, onde afirma que na execução de tais políticas de inclusão elas podem ser insuficientes quando nos remetemos ao atendimento nas regiões que se encontram em desequilíbrio. 
Ainda sobre as políticas Panizzi (2004, p. 66) afirma que existe "a necessidade do estabelecimento de políticas voltadas para ampliação da oferta, ocupação plena das vagas e permanência dos alunos". O que mostra o quão imprescindível é repensar a respeito da classe de renda baixa, o que engloba em muitas das vezes a realidade destes trabalhadores estudantes, e as políticas que se dizem estar voltadas a eles. Bem como a permanência dos mesmos enquanto se mantem no labor de trabalhar e estudar, Sarkis (2004, p. 96) destaca que:

[...] no Brasil, [...] a equidade de acesso só é válida se houver também condições de permanência no ensino superior, que não discrimine as condições sociais, econômicas e culturais do estudante [...], pois, mesmo com a classificação feita no vestibular à evasão é elevada atingindo mais intensamente as classes sociais menos favorecidas.

Dessa forma quando notamos esta realidade de entrada e permanência deste acadêmico de forma geral e total, logo é possibilitado vislumbrar que o labor, o qual tal individuo está incluso apresenta exigências funcionais diariamente, impedindo-o de muitas atividades que se encontram vinculadas a universidade, como afirma Zago:

O tempo investido no trabalho como forma de sobrevivência impõe, limites acadêmicos, como na participação em encontros organizados no interior ou fora da universidade, nos trabalhos coletivos com os colegas, nas festas organizadas pela turma, entre outras circunstâncias. Vários estudantes se sentem à margem de muitas atividades mais diretamente relacionadas ao que se poderia chamar investimentos na formação (congresso, conferências, material de apoio), como relata Ana, estudante de serviço social: Não participo da comunidade universitária Há uma luta constante entre o que gostariam de fazer e o que é possível fazer, materializada em uma gama variada de situações: carga horária de trabalho, tempo insuficiente para dar conta das solicitações do curso e outras, de ordem social e cultural, condicionadas pelos baixos recursos financeiros privar-se de cinema, teatro, espetáculos, eventos científicos, aquisição de livros e revistas. (ZAGO, 2006, p. 235)

No que tange as afirmativas anteriores acerca da relação existente entre a formação acadêmica do psicólogo e o trabalho durante o tempo da universidade, pode-se perceber que tal experiência vivenciada pelos acadêmicos são ambíguas em aspectos como: exigências de tempo. O que se mostra cada vez mais como um trajeto que 
universitários vivenciam conforme a realidade de muito dos estudantes de psicologia do Centro Universitário de Mineiros, retratado no gráfico 1.

\section{CONSIDERAÇÕES FINAIS}

A partir do grau de complexidade do estudo aqui desenvolvido, onde procurou levar em consideração tanto os dados quantitativos, representado pelos gráficos e tabulação dos mesmos, como a análise crítico-reflexiva da proposta inicialmente exposta no artigo e explanada no decorrer do texto, nos remetermos a problemática exposta, esta que gira em torno do questionamento que se refere, aos acadêmicos em sua vida ativa universitária que conciliam o trabalho externo com os seus estudos de forma a agregar valor entre conhecimento obtido na universidade e o labor do trabalho?

Fundamentado nos teóricos aqui já citados podemos por hora sustentar a ideia de que, ao estar sujeitado aos dois universos, o trabalho e a universidade, este acadêmico está sujeito a ter que se subjugar a ideia de não ter a possibilidade de agregar uma gama maior de conhecimento, pois em muito dos momentos que são apresentados tais oportunidades ele estaria em seu trabalho.

Assim como apresentado pela pesquisa e os resultados obtidos pela tabulação dos dados, fica evidente a existência de grupos que se diferenciam segundo a forma que vivenciam a realidade de estar na universidade. Alguns deles com a possibilidade de estudar integralmente, e outros que trabalham e estudam. Estes que se mantem na universidade, apesar das diversas problemáticas, buscam individualmente ou em grupo superar limitações as quais estão submetidos, e evidenciam o propósito e a motivação que os mantem. Com isso, entende-se que de forma premente, há necessidade de investimentos em políticas públicas de ensino superior de qualidade e ainda, que se desenvolvam de forma menos opressora para que este acadêmico, que estuda e trabalha, consiga ter o seu diploma de graduação e/ou licenciatura com saúde mental. Pois, ao reportarmos as políticas que no presente momento nos referimos as educacionais e trabalhistas, a priori faz-se necessário uma completa revisão acerca da permanência no ensino superior, com propósito de beneficiar os 
indivíduos que em verdade necessitam, isso englobando os trabalhadores-estudante, a ponto de terem a possibilidade de estarem presentes em atividades que se referem a sua formação, oferecida pela universidade. Cavalcante (2014) vem afirmar acerca da necessidade do cumprimento das leis que regem as políticas públicas de ensino, onde mostra que existe uma minoria que tem a oportunidade de acessar uma universidade de qualidade, onde primordialmente os indivíduos que tem a necessidade de cumprir três jornadas diárias, em que a terceira se refere ao tempo em que ele se encontra na sala de aula.

Por fim, ainda é validado salientar que tais investigações aqui apresentadas então abarcadas pela perspectiva humana da educação, do trabalho, bem como da sociedade, esta que achar-se á atravessada por um processo que se mantem em constante construção, possuindo verdades que sejam finitas. Nunca se findando, mas sim, transformando e acrescentando como a capacidade de promover-se através das futuras pesquisas.

\section{REFERENCIAS}

BORGES-ANDRADE, Jairo Eduardo; DO PRADO PAGOTTO, Cecília. O estado da arte da pesquisa brasileira em psicologia do trabalho e organizacional. Psicologia: teoria e pesquisa, v. 26, n. 25ANOS, 2010.

BRASIL. Presidência da República Casa Civil. LEI № 11.788, DE 25 DE $\begin{array}{lllll}\text { SETEMBRO } & \text { DE } & 2008 . & (\mathrm{s} / \mathrm{d}) . & \text { Disponível }\end{array}$ http://www.planalto.gov.br/ccivil_03/_ato2007-2010/2008/lei/111788.htm Acesso em: 30 de outubro de 2018.

BRASIL. Constituição da República Federativa do Brasil. Senado Federal: 2012. CAVALCANTE, MCLP. Políticas de Educação Superior: Acesso e permanência de estudantes trabalhadores dos cursos noturnos (1996-2006). 2014.

COLOMBO, Irineu Mario, BALLÃO Carmen Mazepa. Histórico e aplicação da legislação de estágio no Brasil. Educar em Revista, Curitiba, Brasil, n. 53, p. 171- 
(1) NUCLEO DO CONHECTMENTO

186, jul./set. 2014. Editora UFPR. Disponível em: http://www.scielo.br/pdf/er/n53/11.pdf Acesso dia 23 de outubro de 2018.

DE PAULA, Maria Fátima Costa; VARGAS, Hustana Maria. A inclusão do estudantetrabalhador e do trabalhador-estudante na educação superior: desafio público a ser enfrentado. Avaliação: Revista da Avaliação da Educação Superior, v. 18, n. 2 , 2013.

FONSECA, João José Saraiva. Metodologia da Pesquisa Científica. 2002.GIL, Antonio Carlos. Como elaborar projetos de pesquisa. São Paulo. 2002.

GISI, Maria Lourdes. Políticas educacionais para a Educação Superior: acesso, permanência e formação. Revista Diálogo Educacional. Curitiba, v. 4, n. 11, p. 4352, jan/abr. 2004.

MESQUITA, Maria Cristina das Graças Dutra et al. 0 trabalhador estudante do ensino superior noturno: possibilidades de acesso, permanência com sucesso e formação. 2010.

PANIZZI, Wrana Maria. A democratização do acesso à universidade pública. In: PEIXOTO, Maria do C. de Lacerda (org). Universidade e Democracia: experiências e alternativas para ampliação do acesso à Universidade pública brasileira. Belo Horizente: UFMG, 2004.

PIROLO, et al. A pesquisa de opinião pública na transformação social. In III Simpósio em Filosofia e Ciência - Resumos, 1999, p. 43)

RAMPAZZO, Lino. Metodologia científica. Edições Loyola, 2005.

RISTOFF, D.; PACHECO, E. Educação Superior: democratizando o acesso. Brasília: Inep, 2004. (Série Documental. Textos para Discussão)

RODRIGUES, Iveti Magalia Caetano; DE LOURDES MACHADO, Maria; DE ARAÚJO, Joaquim Filipe Ferraz Esteves. Expansão do Ensino Superior no Brasil: avaliação como mecanismo para a garantia da qualidade. comunicação apresentada para o $1^{\circ}$ 
Fórum do Ensino Superior nos Países e Regiões de Língua Portuguesa, Universidade de Lisboa e Universidade de Coimbra, v. 14, 2011.ROMANELLI, Geraldo. O significado da escolarização superior para duas gerações de famílias de camadas médias. Revista Brasileira de Estudos Pedagógicos, v. 76, n. 184, p. 445476, set./dez. 1995.

ROMANELLI, Geraldo. Autoridade e poder na família. A família contemporânea em debate, v. 3, 1995.

SANTOS, Milton. Pensando o espaço do homem. Edusp, 2004.

SARKIS, Paulo Jorge. Equidade de acesso à educação Superior: o caso da UFSC. In: PEIXOTO, Maria do C. de Lacerda (org). Universidade e Democracia: experiências e alternativas para ampliação do acesso à Universidade pública brasileira. Belo Horizente: UFMG, 2004.

VERGARA, Sylvia Constant. A utilização da construção de desenhos como técnica de coleta de dados. Pesquisa qualitativa em administração. Rio de Janeiro: FGV, 2004.

YAMAMOTO, Osvaldo Hajime; BORGES, Lívia de Oliveira. O mundo do trabalho. ZANELLI, José Carlos; BORGES-ANDRADE, Jairo Eduardo; BASTOS, Antonio V. Bittencourt. Psicologia, organizações e trabalho no Brasil. Porto Alegre: Artmed, 2004.

ZAGO, Nadir. Do acesso à permanência no ensino superior: percursos de estudantes universitários de camadas populares. Revista Brasileira de Educação. Rio de Janeiro, v. 11, n. 32, 2006.

ZANELLI, José Carlos. O psicólogo nas organizações de trabalho. Artmed Editora, 2002.

Enviado: Outubro, 2019.

Aprovado: Outubro, 2019. 